\title{
Construction and Application of Practice Teaching Model based on Network Cooperative Learning
}

\author{
Xiaowei $\mathrm{Jia}^{1}$, Lili Zhang ${ }^{1}$, Ke Huang ${ }^{1}$ \\ ${ }^{1}$ School of Mechanical and Electrical Engineering, Jiangsu Vocational College Agriculture and Forestry, \\ Jiangsu 212400, China.
}

Keywords: practice teaching; network cooperative learning; multi-modal; interdependence

\begin{abstract}
In traditional practice teaching, teachers get the low teaching efficiency and unsatisfactory teaching results, because of cannot take into account each student. This paper discussed how to improve practice teaching efficiency with web. Taking CNC technology course as an example, this paper built and analyzed a practice teaching model based on network cooperative learning from four aspects: situation, collaboration, conversation and meaning. And this paper selected two independent teaching sections for comparative teaching. Through questionnaires and parts processing, this paper multi-modal evaluated the actual effect of new practice teaching model. This paper found a method that builds a fusion practice teaching mode, to help teachers to improve teaching effects. The model fused two platform (offline platform and online platform), connected three learning sections (pre-learning section, learning section, post-learning section), and linked four parts (subject part, basic part, development part, show part). In the fusion practice teaching model, it encourages students to cooperate and help each other, cultivate students' habits of interdependence; encourages students to actively participate in practice, enhance students' technical ability; encourages students to share with each other, improve learning efficiency, and improve teaching effects.
\end{abstract}

\section{Introduction}

The process of learning is the process of establishing a link between new knowledge and old knowledge. In traditional classroom, the teacher is to teach and students are to be learned. They are both tired. Because there are many students in the class, teachers can't take care of each student, causing dependent students to learn in excess and independent students can't learn enough.

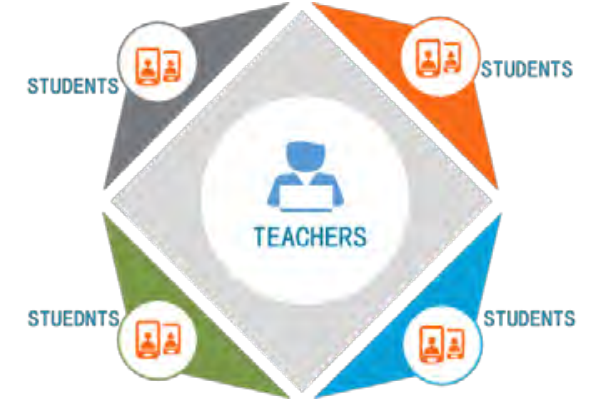

Fig. 1 Relationship of traditional teaching

In internet learning, dependent students are easy to give up learning by themselves without a learning atmosphere and without supervision. Moreover, not all knowledge can be learned in self-study, especially in practical content. And online video cannot show every skill detail.

Cooperative learning requires students to engage in learning activities together in a heterogeneous group to jointly complete the assignment tasks assigned by the teacher [1]. In cooperative learning, dependent students can define their learning goals better and strengthen their motivation in the atmosphere of team learning. It can enable independent students to lead team members, organize team activities, and help team members to complete tasks in cooperative learning. Consolidate learning outcomes, exercise comprehensive ability, and gain more sense of accomplishment; it can free teachers from heavy repetition of answering students' questions, have more energy to organize teaching, guide students how to learn, and better solve the existence of learning process. 


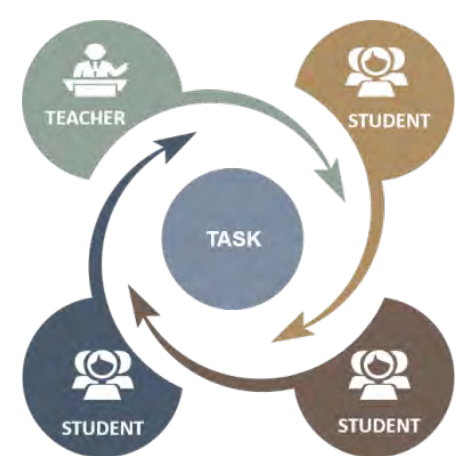

Fig. 2 Relationship of cooperative learning

Network cooperative learning use network and other related technologies, cooperative learning teaching strategies, and the internet characteristics and resources. And it supports and incentives for cooperative learning, establishes a meaningful learning environment, and promotes student learning activities [1].Therefore, teachers combine the respective advantages of internet learning and cooperative learning to establish an open, equal and relaxed learning environment. Students gradually complete the transformation of "dependency- independence- interdependence" in this environment.

\section{What's Network Cooperative Learning}

Cooperative learning is a mutual aid learning that students have a clear division of responsibility in order to accomplish common tasks [2]. Through reasonable grouping, effective supervision and guidance, and scientific evaluation, the teaching process can be better solved. Internet can take advantage of the network platform to overcome the time and space limitations of offline learning [3], so that learners can learn materials repeatedly and improve their learning. The traditional offline cooperative learning group is usually divided into groups by fixed. Many teachers can't participate in the discussion of each group. It is also impossible to effectively supervise. Learning evaluation often only examines explicit indicators such as task completion.

Network cooperative learning is not a simple superposition of internet and cooperative learning, but it is to use internet thinking and technology to transform and even subvert the traditional cooperative learning [4]. Network cooperative learning relies on the network platform to reorganize traditional cooperative learning through big data technology, changes students to be organizers and monitors of cooperative learning, stimulates students' learning motivation by fully opportunities, and makes their thinking and discussion. The learning goal is not only to complete the task, but to deeply think about the content of the study, and continuously asks the process of discussion. The network cooperative learning is a hybrid model that combines the openness, wide-area and interactivity of internet learning with the intuitiveness, accuracy and vividness of teaching. [5].

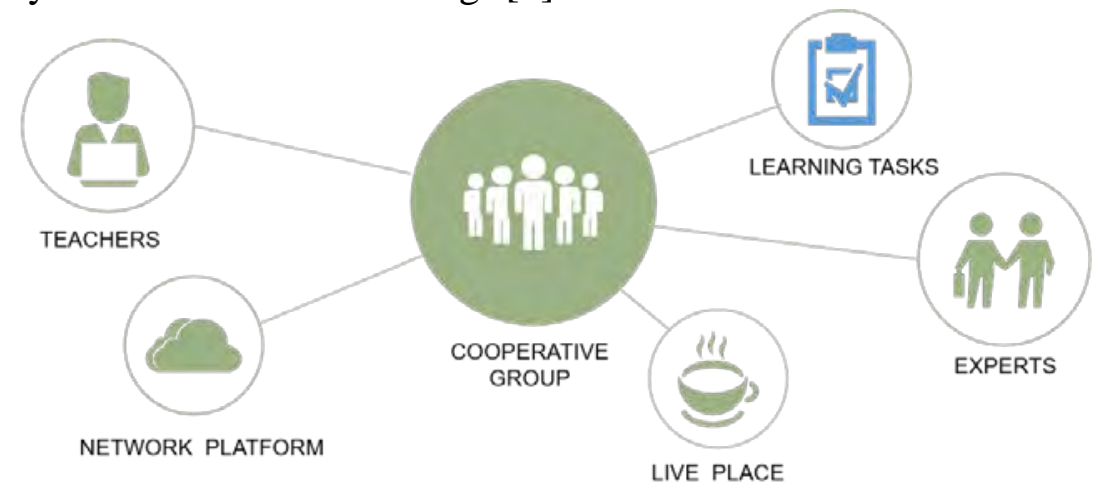

Fig. 3 Relationship of network cooperative learning

The network cooperative learning has three basic teaching elements, namely, cooperative groups, teachers, and learning tasks [6]. The cooperative group is the basic organizational form of network cooperative learning. In the network cooperative learning, teachers go from the center of teaching to the 
periphery of learning, but not outsiders, as researchers, guides and collaborators. teachers give students guidance and feedback to problems that students cannot solve or raise, mainly responsible for organization, monitoring, and coordination [6]. Learning tasks are the basic goal of network cooperative learning, so that students have clear goal and will not be lost in the "useless" information of the network.

\section{Building Practice Teaching Model Based on Network Cooperative Learning}

Based on the internet environment, network cooperative learning combined with classroom teaching. It made students' activities to become a common activity, the achievement of learning objectives as the driving force, and interaction as the main form [7]. In the process of network cooperative learning, students are the masters of learning activities. The focus of research was on the students' learning, and the subjective consciousness of cultivating students' active cooperation was always used throughout practice [7]. "I hear and I forget. I see and I remember. I do and I understand." Compared with traditional cooperative learning, online cooperative learning further strengthened the practical and experiential nature of the student learning process. Teachers encouraged students to participate bravely, consolidate emotional experiences, strengthen skills practice, and gradually realized the construction of learning experiences from simple to complex.

CNC technology course is a professional course for engineering majors. Taking the content of CNC programming operation as an example, this paper built and analyzed practice teaching model based on network cooperative learning. According to constructivist theory, it constructed a practice teaching model from four aspects: situation, collaboration, conversation, and meaning. On the basis of students' active learning, they formed mutual positive mutual cooperation. Members encouraged and promoted learning efforts each other[8], and ultimately condensed into the team's positive cohesion.

The teaching of CNC programming generally involved two steps: NC programming and part processing. At the writing stage of the NC program, it was necessary to explain the programming requirements of the $\mathrm{CNC}$ system, the part process discussion, and the part processing program; the part processing stage needed to master the CNC machine tool operation method, and used the CNC machine tool for part processing. This part of the teaching content was a combination of theory and practice. It met the characteristics of network cooperative learning collaboration, interdependence, practical experience, etc., suitable for the use of network cooperative learning teaching model.

Combined with the above analysis, the practice teaching model constructed by CNC technology course (shown in Fig. 4) includes two platforms, three sections and four parts. The two platforms are independent and closely linked, and the three sections are connected one after another. The four parts have division and common tasks. 


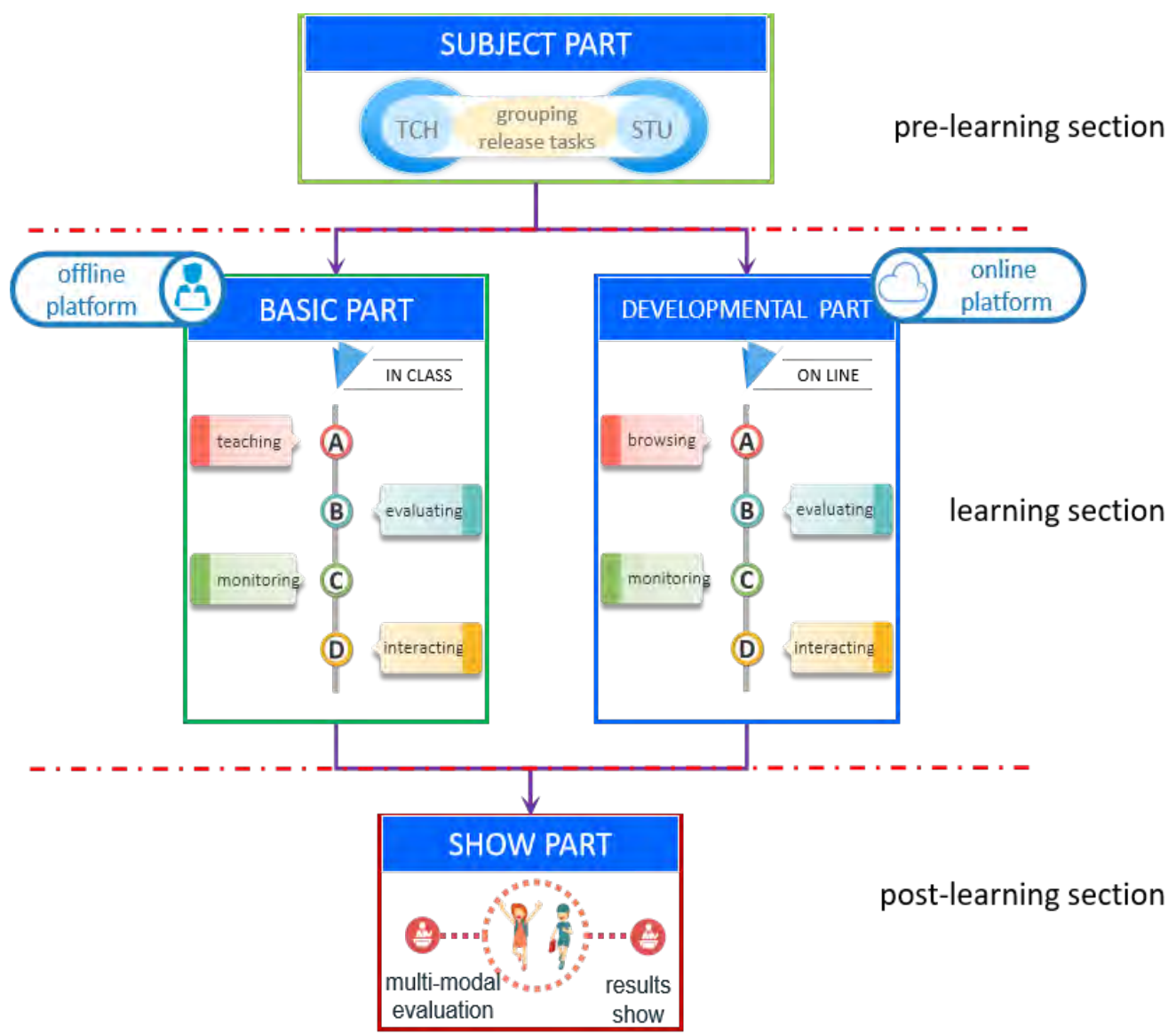

Fig. 4 Structure of practice teaching model

The two platforms were the offline platform and the online platform. The offline platform was mainly engaged in classroom teaching practice activities, and the online platform mainly conducted network expansion discussion activities. The platforms were fused.

The three sections were divided into pre-learning section; learning section and post-learning section, which respectively correspond to preparation, task release, mutual cooperation, task completion, evaluation, task display etc.

The four parts were subject part, basic part, development part, show part. Subject part: before the task starts, the teachers (or students) were grouped according to the purpose and content of the study, and the cooperative learning task was released. Cooperative learning tasks were divided into two categories, one was basic tasks, mainly the completion of classroom cooperative learning, teachers and students interacted directly and cooperated with each other; the other was extended tasks, mainly deep high-level tasks, allowing students to network platforms cooperate and even consult industry experts. The main function of the show part was to evaluate the learning outcomes. Due to the difference in learning objectives and learning ability of students, the evaluation of learning outcomes was a multi-modal cooperative evaluation[9]. After group discussion, the collective practice was showed by physical objects, pictures, video and other forms.

\section{Analysis the Practice Teaching in Network Cooperative Learning}

\subsection{Introduce the Practice Teaching method}

Taking 39 students as the research object. In the way of teaching, the two teaching parts were relatively independent and the difficulty was equal. 


\subsection{Evaluating the result of practice teaching}

\subsubsection{Method of evaluating}

The test used two methods: questionnaires and machining parts. The test was divided into two teaching parts: thread part and subprogram part. The two parts had no relationship. The thread part was taught by traditional cooperative learning method, and the subprogram part was taught by network cooperative learning method. The questionnaires were tested after the end of two parts teaching. The questionnaire contained three aspects: self-confidence, interest and skills. There were 10 questions in each case. There were four options in the form of multiple-choice questions. Each option represented 3, 2, 1, and 0. The representative was "very consistent", 2 stood for "basic conformity", 1 stood for "difficult to judge", and 0 stood for "very non-conformity".

4.2.2 Analysis the result

After students learning two parts, all the data obtained were statistically analyzed. The comparison between the thread part and the subprogram part was performed using an independent sample $\mathrm{T}$ test, as shown in Table 1.

Table 1 Independent sample T test for thread structure part and subroutine structure part

\begin{tabular}{|c|c|c|c|c|c|c|}
\hline & \multicolumn{2}{|c|}{ Thread part } & \multicolumn{2}{c|}{ Subprogram part } & \multirow{2}{*}{$\mathrm{T}$} & \multirow{2}{*}{$\mathrm{P}$} \\
\cline { 2 - 6 } & Average & Standard deviation & Average & Standard deviation & & \\
\hline Self-confidence & 16.231 & 2.401 & 17.590 & 2.227 & -2.558 & 0.013 \\
\hline Interests & 19.718 & 3.029 & 21.154 & 2.751 & -2.163 & 0.034 \\
\hline Skills & 18.179 & 2.951 & 20.436 & 2.216 & -3.768 & 0.000 \\
\hline
\end{tabular}

Table 1 shows that the thread part and the subprogram part have significant differences in the scores of self-confidence, interests and skills. $\mathrm{P}<0.01$ is measured in practice, and the difference between the thread part and the subprogram part is compared in all aspects. It can be considered that network cooperative learning is conducive to the comprehensive and coordinated development of students' comprehensive quality, and has a great impact on students' emotional experience and learning skills.

\subsection{Result of Practice Teaching}

The practical results show that the network cooperative learning adopts the multi-modal evaluation method for the students' learning objectives, abilities and specialties through online and offline combination, which can effectively help students to improve.

4.3.1 The network cooperative learning encourages students to collaborate and help each other to cultivate students' habits of interdependence.

Network cooperative learning overcome the loneliness of students and enhances students' self-confidence through online and offline cooperation and communication. Network cooperative learning strengthens collaboration and mutual respect, enhances students' expressive ability and enriches students' emotional experience.

4.3.2 The network cooperative learning encourages students to actively participate in practice and enhance students' technical ability

Network cooperative learning enhances learning confidence through collaboration and mutual assistance. At the same time, the mutual learning environment also plays a role in reminding each other, encouraging dependent students to participate in practice, increasing interest in learning, improving skill levels, and improving the overall level of the team.

\section{Summary}

Network cooperative learning breaks through the limitations of time and space. Teachers, experts and students can seamlessly connect, strengthen cooperation and exchange, strengthen emotional experience, and strengthen practical ability. The practice teaching model fuses offline and online, uses the advantage of class teaching and internet teaching, improve teaching efficiency. 


\section{References}

[1]. Su Bin, Network cooperative learning under the concept of difference teaching, Shandong: Shandong Normal University, 2011.(In Chinese)

[2]. Cui Zhiwei, Cooperative Learning Change under the Background of “Internet +",Teaching Monthly • Mid-school Edit(Chinese Teaching), 2017, (Z2): 81-84.(In Chinese)

[3]. Mu-Yu Ting. A Study of Cooperative Learning Strategy to Calculus by applying the Computer-Assisted Instruction-using Computer Science \& Information Engineer of some University as an example, Journal of National Formosa University, 2009, 28(1): 27-39.

[4]. Chu Jun, He Xuexin, The connotation of "Internet + cooperative learning", Teaching and Management, 2017, (18): 77-79.(In Chinese)

[5]. Shao Qinyu, He Li, Mode Construction and Empirical Research on Cooperative College English Learning on the Basis of Web and Classroom Environments, Foreign language electrification teaching, 2014, (2): 31-35, 47.

[6]. Guan Zhongke, Search is Learning, Distance education, 2009, v.17;No.192(3): 82.(In Chinese)

[7]. Tang Yingping, Theoretical and Practical Research on Cooperative Learning in Multimedia Network Environment, Shanghai: Shanghai Normal University, 2004.(In Chinese)

[8]. Ding Li, Adult Cooperative Learning Strategies on Network Environment, Sichuan: Sichuan Normal University, 2014.

[9]. Liu Dongli, “Internet+” and an Application Research of Multi-modality Teaching Mode in College English Writing , Journal of Qiqihar University (Phi \& Soc Sci), 2017, (2): 186-188. 